\title{
Extracorporeal membrane oxygenation for the treatment of postcardiotomy shock
}

\author{
Glenn J. R. Whitman, MD
}

\begin{abstract}
Use of extracorporeal membrane oxygenation (ECMO), one of an increasing variety of mechanical circulatory support strategies, was first used close to 50 years ago. For decades, it was mostly applied to the pediatric population. However, during the past several years, its use has dramatically increased as therapy for pulmonary and cardiac failure in the adult. In particular, ECMO is being used more and more for postcardiotomy shock. Unfortunately, despite its increased application in this setting, improved outcomes have been hard to come by. Improved results must be grounded on an approach that honors the tenets of myocardial recovery, minimizing the work done by the heart during the recovery period. Left ventricular decompression should be a tenet of ECMO support in the setting of postcardiotomy shock, universally applied if we are to see any significant improvement in our results. Furthermore, the point is made that surgeons should play a leadership role in the immediate counseling of patients' families to assure realistic expectations on their part. To address the need for family support during this very difficult time, ECMO centers should design a programmatic approach to care for patients and their families so as to provide them with education, guidance, and emotional support. (J Thorac Cardiovasc Surg 2017;153:95-101)
\end{abstract}

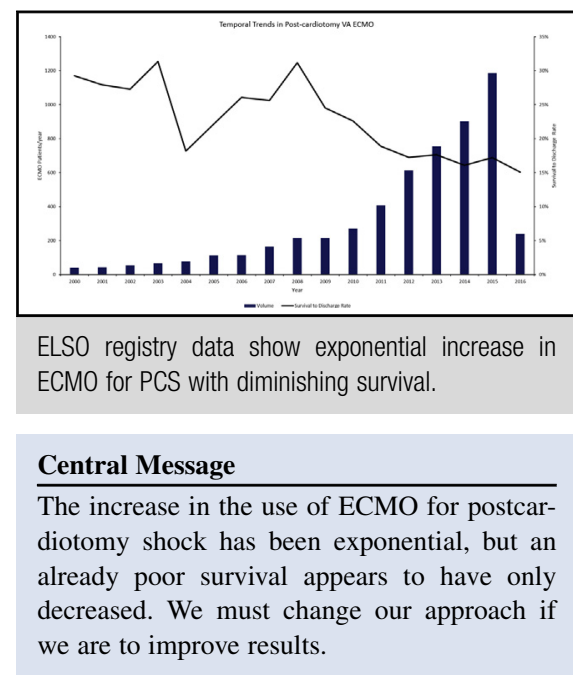

See Editorial Commentary page 102.
Feature Editor's Note-Mechanical circulatory support, in the form of extracorporeal membrane oxygenation (ECMO) has become a powerful adjuvant to the care of patients with cardiac or respiratory failure. In the past decade, we have seen unprecedented adoption and dissemination of ECMO, driven in part by technologic improvements that have facilitated institution of the therapy as well as management of the patient during support. As with any advanced technology that is rapidly disseminated in the medical field, however, significant concerns arise regarding how best to assess the overall benefit and impact that come with the process of dissemination. This particularly applies to new applications of the therapy. Importantly, comparisons of institutional and individual practices, patient selection processes, and patient outcomes are important to assessing overall impact and

\footnotetext{
From the Division of Cardiac Surgery, Department of Surgery, Johns Hopkins School of Medicine, Baltimore, Md.

Received for publication June 13, 2016; revisions received July 25, 2016; accepted for publication Aug 1, 2016; available ahead of print Sept 22, 2016.

Address for reprints: Glenn J. R. Whitman, MD, Johns Hopkins School of Medicine, Director, CVSICU and Heart Transplant, Johns Hopkins Hospital, Sheikh Zayed Tower, Suite 7107, 1800 Orleans St, Baltimore, MD 21287-4618 (E-mail: gwhitman@jhmi.edu).

$0022-5223 / \$ 36.00$

Copyright (C) 2016 by The American Association for Thoracic Surgery

http://dx.doi.org/10.1016/j.jtcvs.2016.08.024
}

benefit. Vital to this process is the availability of prospectively collected rigorous scientific data describing patient characteristics as well as treatment practices. It is important as ECMO is disseminated to realize the improvements in outcomes with time that reflect increasing experience and knowledge while maintaining principles of care and management that have been demonstrated to lead to successful outcomes. As with any advanced technology that has significant lifesaving capabilities, rapid dissemination carries with it issues such as cost and ethics that complicate the overall assessment of benefit and impact. ECMO is a vital and important therapy for treatment of refractory cardiac or respiratory failure. ECMO therapy would benefit from greater collaboration by its users to assess uniformity of practice and patient outcomes to permit ongoing rigorous evaluation of its benefit for both established indications and new applications of this technology.

\section{Frank D. Pagani, MD}

Extracorporeal membrane oxygenation (ECMO) was first described in 1972 by Hill and colleagues ${ }^{1}$ after its successful use for a 24-year-old who had severe acute respiratory 


\section{Abbreviations and Acronyms \\ $\mathrm{ECMO}=$ extracorporeal membrane oxygenation \\ PCS $=$ postcardiotomy shock \\ NIS = National Inpatient Sample \\ ELSO = Extracorporeal Life Support Organization \\ STS $=$ Society of Thoracic Surgeons \\ ICU = intensive care unit}

distress syndrome develop after a motor vehicle crash. After another success in 1975, the National Institutes of Health sponsored a multicenter ECMO trial randomly assigning adults to receive 1 week of venoarterial ECMO or traditional mechanical ventilator support. ${ }^{2}$ Mortality was $90 \%$ in both arms, despite higher costs and greater resource use with ECMO, signaling a lack of benefit to all but the most adamant believers.

Thereafter adult ECMO remained quiescent, until it was revived 25 years later by the influenza epidemic in 2007 through 2009. At that point, adult ECMO for acute respiratory distress syndrome took off (Figure 1), with a $50 \%$ to $60 \%$ survival, a remarkable improvement from the National Institutes of Health trial.

ECMO for respiratory failure has been paralleled by an increase in its use for shock from any cardiac cause (Figure 2), including postcardiotomy shock (PCS), the subject of this article. In a recent analysis of ECMO as therapy for PCS in the United States between 2002 and 2012, McCarthy and colleagues ${ }^{3}$ reviewed a total of 87 million records from the National Inpatient Sample (NIS) and showed an order of magnitude increase in ECMO for PCS. The NIS is derived from the Healthcare Cost and Utilization Project, created under the aegis of the Agency for Healthcare Research and Quality. It is the largest publicly available all-payor database for inpatient care in the United States.

In their analysis, ECMO therapy in the face of PCS had a $60 \%$ mortality which, along with cardiogenic shock, represented the highest mortality for all ECMO indications. Corroborating this observed mortality for ECMO as therapy for PCS, Fukuhara and associates ${ }^{4}$ reviewed the effectiveness of all mechanical circulatory support for PCS in 22 studies published between 1993 and 2015. The support ranged from intra-aortic balloon pumps to short-term ventricular assist devices to venoarterial ECMO. First, and most importantly, the point was made that there is no consensus definition for PCS, and as a result we suffer from an inability to understand how best to treat it. Second, for every study survival rates were discouraging, ranging from $25 \%$ to $50 \%$. Whether treated with a balloon pump, a temporary ventricular assist device, or venoarterial ECMO, however, the outcomes are difficult to analyze because the surgeons' triggers for their use may have varied widely. In no study was were the triggers well characterized. All studies specifically of ECMO for PCS suffer similarly, and as a result there is no easily definable comparison group that might help us to understand the benefits of mechanical support for PCS. Regardless, during the almost 25-year period that encompassed the review of Fukuhara

ECMO For Respiratory Distress

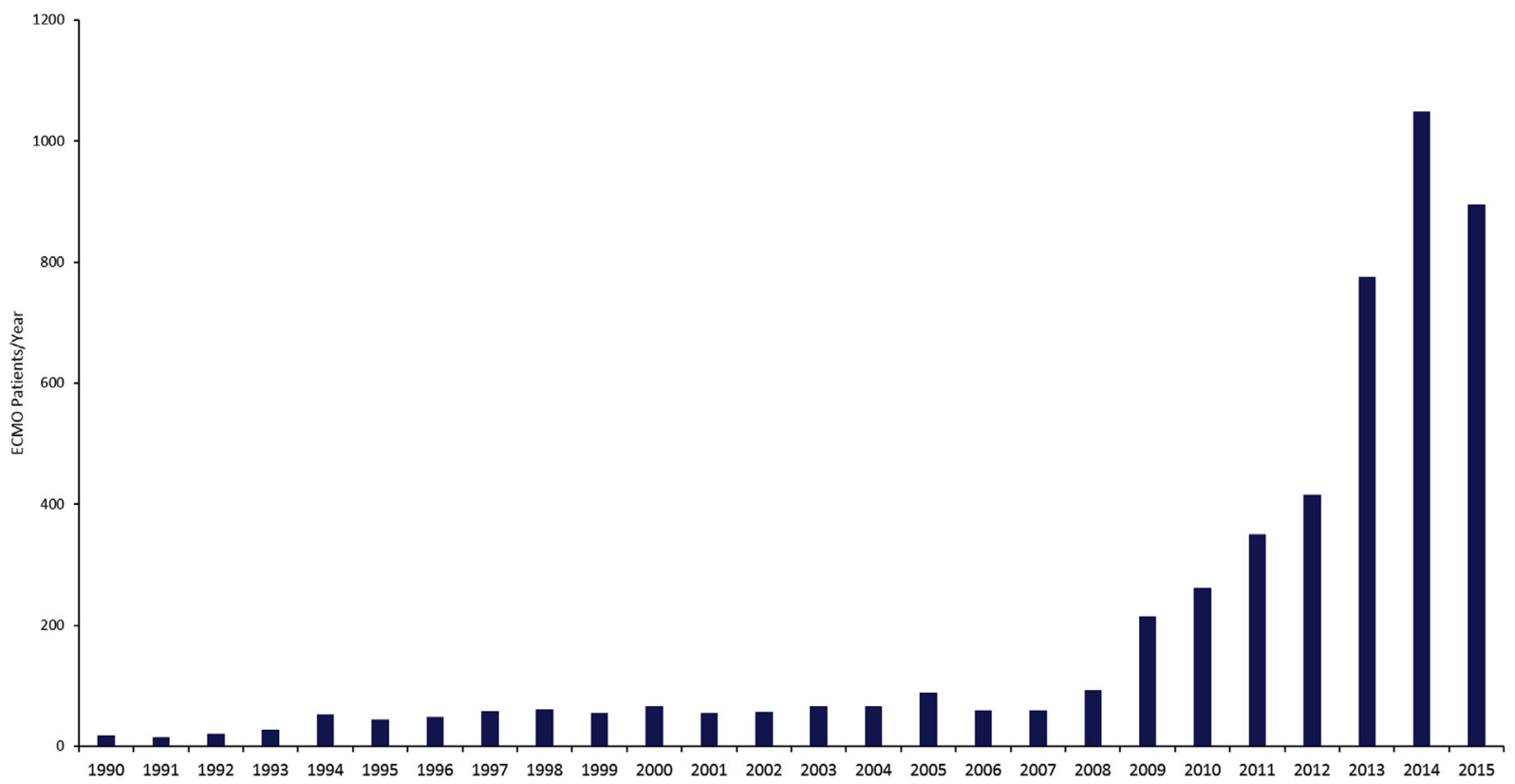

FIGURE 1. Taken from the US Extracorporeal Life Support registry, this graph shows the exponential increase in the use of extracorporeal membrane oxygenation $(E C M O)$ for all respiratory diagnoses during the last 10 years. 
ECMO For Cardiogenic Shock

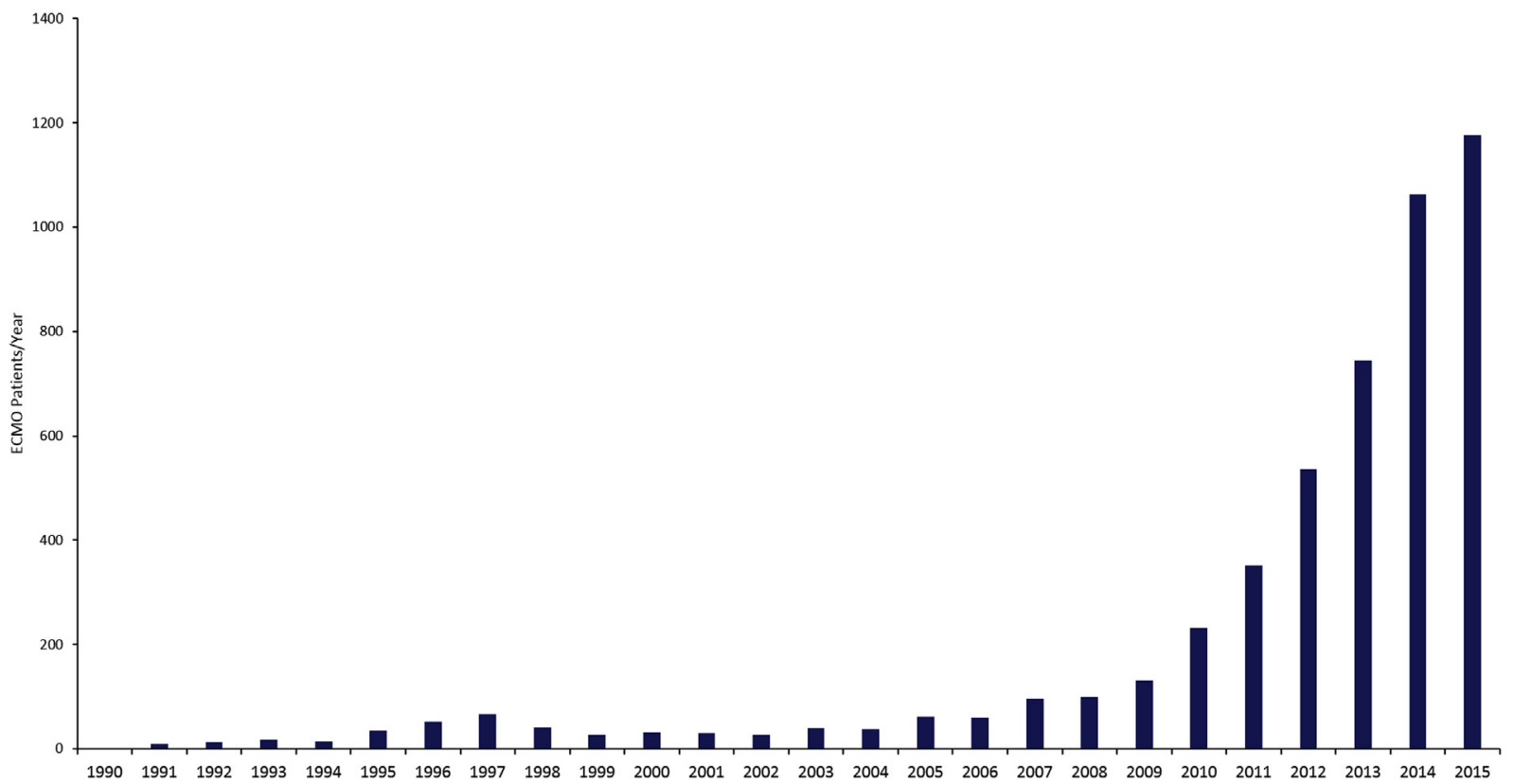

FIGURE 2. Taken from the US Extracorporeal Life Support registry, this graph, which parallels the respiratory experience, shows the increase in the use of extracorporeal membrane oxygenation $(E C M O)$ for all cardiac diagnoses during the last 10 years.

and associates ${ }^{4}$ mechanical support does not appear to have improved the outcome for PCS. In a 15-year analysis of the Extracorporeal Life Support Organization (ELSO) database, the results seen specifically for ECMO in PCS are similarly very disappointing. Although the ELSO data confirm that ECMO has increased exponentially for the treatment of PCS, it appears that survival rates to discharge have, if anything, decreased (Figure 3).

In an attempt to understand ECMO for PCS at a more granular level, the most informative and largest singleinstitution study to draw from is that by Rastan and colleagues $^{5}$ in 2010 , which reported on more than 40,000

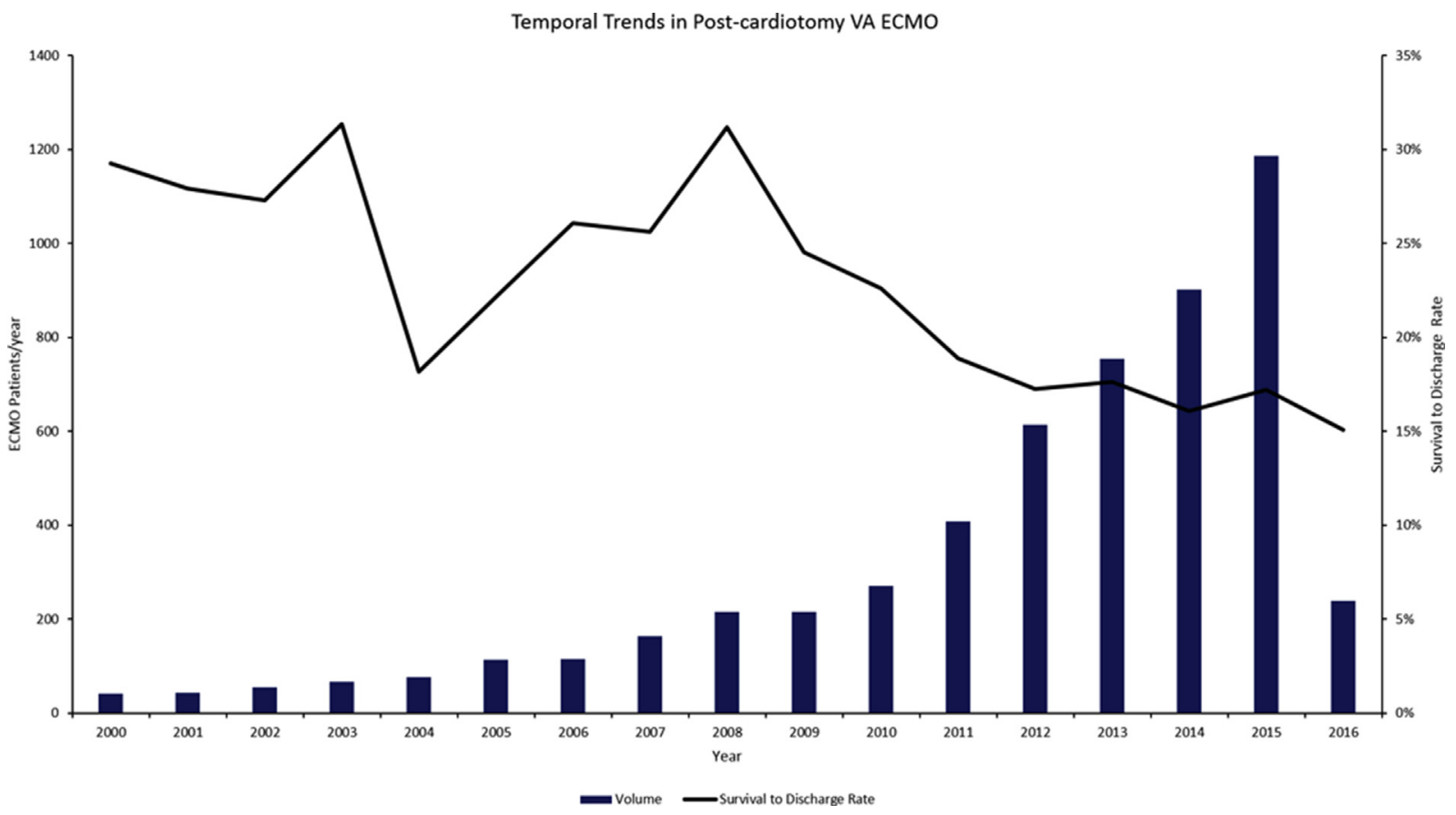

FIGURE 3. Data abstracted from the ELSO database show the exponential increase in extracorporeal membrane oxygenation (ECMO) for PCS. This increase unfortunately appears to be associated with a diminishing survival. VA, Venoarterial. 
patients, among whom $517(1.2 \%)$ required ECMO for PCS. Among their patients, $70 \%$ fell into the Society of Thoracic Surgeons (STS) category of a major case (isolated coronary, isolated valve, or a combination). ECMO was instituted intraoperatively in $40 \%$ of patients, and cannulation was central in just over $60 \%$. Complication rates were high, with the 2 most common complications being postoperative hemorrhage, with an average of 30 units of blood products transfused per patient (13 units of red blood cell transfusions per patient), and renal failure requiring dialysis, occurring in $65 \%$ of the patients. Notably, ECMO was instituted in $60 \%$ of patients after admission to the ICU, rather than as an immediate aid to separation from bypass, with an average of 2.5 days between ICU admission and institution of ECMO. Second, although close to two-thirds of the entire cohort were able to be weaned from ECMO within 3 to 4 days, fewer than half of those who were weaned ultimately survived to discharge. Surprisingly, this survival of $25 \%$ was unaffected by the decision to provide ECMO support intraoperatively or during the postoperative ICU course. In the cohort with ECMO instituted after ICU arrival, however, delay in institution was associated with poorer survival. One has to assume that something nearly catastrophic must have occurred to necessitate the institution of ECMO in the ICU; this point is not clarified, however, again pointing out the need for a standard definition of PCS. Regardless, during the 12 years covered in this study, the mortality for PCSassociated ECMO was $75 \%$, with no trend towards improvement throughout the duration of the study (Table 1).

There are, however, insights to be gained by reviewing some of the more recent studies that I believe may lead to improved outcomes. First and foremost, when ECMO is used for PCS, there are no uniform criteria for when or how to institute it. Although any study on the subject will represent a "how we do it" analysis, we must require a thorough description of who these patients were and just what was done, so we can learn as much as possible from the experience. Second, although it appears that the survival of patients with PCS is poor and not improving, we do not know this for certain, because comparison cohorts do not exist. If one presumes that all patients would otherwise have died, a $25 \%$ to $50 \%$ survival is more than encouraging. There actually are data on a similar group of patients, however, and these data give us a hint as to how these patients might fare if treated with drugs and an intra-aortic balloon pump. Samuels and coworkers ${ }^{6}$ analyzed more 3500 patients for the incidence and outcomes of PCS. Samuels and coworkers ${ }^{6}$ identified a specific group, $1.5 \%$ of the entire cohort (surprisingly similar to the incidence described by Rastan and colleagues ${ }^{5}$ in their 40,000 patients) who had postbypass shock characterized by elevated filling pressures and a cardiac index less than $2 \mathrm{~L} / \mathrm{min}$ despite 3 high-dose pressors. In that population, the mortality without ventricular assist support was $83 \%$ (19 of 23
TABLE 1. Analysis of technical variables and outcomes associated with the extracorporeal membrane oxygenation experience presented in the largest series of patients in the literature

\begin{tabular}{lc}
\hline \multicolumn{1}{c}{ Phase of care } & $\begin{array}{c}\text { Intraoperative, } \mathbf{4 0} \% ; \\
\text { postoperative, } \mathbf{6 0} \%\end{array}$ \\
\hline Cannulation & Central, $60 \%$; peripheral, $40 \%$ \\
ECMO duration & $3.3 \pm 2.9 \mathrm{~d}(0-25 \mathrm{~d})$ \\
IABP used & $74 \%$ \\
Complications & \\
Hemorrhage & $3100 \mathrm{~mL}$ in first $24 \mathrm{~h}$ \\
Renal failure & $65 \%$ \\
Reoperations & $64 \%$ \\
Gastrointestinal complications & $19 \%$ \\
Stroke & $17 \%$ \\
Leg ischemia & $20 \%$ \\
Survival & \\
Through ECMO & $63 \%$ \\
To discharge & $25 \%$ \\
At 6 mo & $18 \%$ \\
\hline
\end{tabular}

Data taken from Rastan and colleagues. ${ }^{5}$ ECMO, Extracorporeal membrane oxygenation; IABP, intra-aortic balloon pump

patients). In this light, perhaps our outcomes of ECMO in PCS need not be viewed so harshly.

Nevertheless, I think that we would all agree that defining the benefits of medical therapy versus mechanical support for PCS may forever be impossible. Only poorly described historical controls are available to us, and in the current era none of us would withhold maximal support for those patients we deem to have a chance at survival. Our only hope to understand the appropriate use of ECMO is to agree on the variables that we think affect outcome in all patients subjected to this rescue therapy and to develop a database that will allow analyses to assess benefit. Table 2 shows variables that, at the very least, should be captured to help us best determine how to treat this group of patients.

\section{HOW CAN WE IMPROVE OUTCOMES FOR PCS TREATMENT WITH ECMO?}

Pertinent to this discussion of outcomes for ECMO in patients with PCS, I think it is worthwhile to cite the analysis of PCS by Hernandez and colleagues, ${ }^{7}$ an STS database-driven study published in 2007. In that study, a 10-year analysis of the treatment of PCS with ventricular assist devices, not ECMO, was undertaken. The analysis looked at all STSreported patients undergoing open heart surgery between 1995 and 2004 and determined that 5735 patients $(0.3 \%$ of the entire STS registry) received ventricular assist device therapy for PCS. Their overall survival was $54 \%$, one of the best study outcomes for PCS. When they broke this down by time period, they showed a more than $50 \%$ reduction in the risk of morbidity and mortality during the last 5 years of the study relative to the first, giving one the impression that PCS was being more effectively treated by all of us during the decade examined, at least if a ventricular assist 
TABLE 2. Proposed data elements to aid in developing best practices for extracorporeal membrane oxygenation in the treatment of postcardiotomy shock

All STS database elements

Time to ECMO from first attempt at $\mathrm{CPB}$ weaning

At time of ECMO decision

CVP and pulmonary arterial pressures

Mixed venous oxygenation saturation and hemoglobin concentration

Pressor dosages at time of ECMO institution

IABP presence

Type of cannulation: cannula type and size, sites of placement

ECMO pump and oxygenator type

$\mathrm{LV}$ vent, and if so, by what approach

Anticoagulation approach

Outcomes including the following:

Days on ECMO

Complications

Survival to ECMO separation, to hospital discharge, $30 \mathrm{~d}$ and 6 mo Use of an ECMO committee, and if so its constituency

$S T S$, Society of Thoracic Surgeons; ECMO, extracorporeal membrane oxygenation; $C P B$, cardiopulmonary bypass; $C V P$, central venous pressure; $I A B P$, intra-aortic balloon pump; $L V$, left ventricular.

device was used. To continue this theme, I would like to highlight another study, the RECOVER 1 trial reported by Griffith and associates, ${ }^{8}$ in which 16 patients at high risk (euroSCORE, $34 \%$; ejection fraction, $23 \%$; congestive heart failure, $88 \%$ ) agreed to the use of an Impella 5.0/LD device (Abiomed, Danvers, Mass) if, at separation from bypass, they appeared to have cardiogenic shock, as manifested by elevated left-sided (but not right-sided) filling pressures, and were receiving "high-dose" pressors, defined as an epinephrine dose greater than $0.03 \mu \mathrm{g} / \mathrm{kg} / \mathrm{min}$ or the equivalent of dopamine or milrinone. As Griffith and associates ${ }^{8}$ admitted in their discussion section, the pressor dose triggering the use of the Impella device was extremely conservative; they were quick to point out, however, that most of their patients were receiving 2 or 3 pressors by the time the device was placed. In fact, a nonrigorous post hoc questioning of Griffith and associates ${ }^{8}$ revealed that they believed that 16 of the 18 patients were headed for mechanical support without question, and that the low-dose pressor dosage used as a trigger for placing the device should be discounted because their patients in fact were in profound cardiogenic shock in the event. The issue of just how poor the myocardial contractility was at the time of device placement is open to debate, but the facts are that the duration of Impella support was 3 to 4 days and survival to discharge was an incredible $93 \%$. These are astronomical survival numbers if we believe, as Griffith and associates ${ }^{8}$ would have us believe, that these patients were in dire straits after cardiotomy.

These studies are intriguing in that (1) they have significantly better outcomes than generally seen for PCS, and (2) both studies involved total $\mathrm{LV}$ decompression as a route to myocardial recovery. The data regarding the deleterious effects of LV distention on recovery goes back decades. As just one example, Lucas and colleagues ${ }^{9}$ showed the dramatic effect of LV distention on recovery of function in canine hearts subjected to 45 minutes of hypothermic cardioplegic arrest. Vented hearts recovered $60 \%$ more function than did hearts exposed to LV end-diastolic pressure of $20 \mathrm{~mm} \mathrm{Hg}$. Furthermore, recent studies of pediatric ECMO in PCS have shown decreased duration of ECMO in patients with left atrial venting. ${ }^{10}$ These studies show a benefit from fully unloading the LV to optimize recovery after an ischemic insult, and I would argue that all of us in the field should consistently vent the left side of the heart in these patients if we are to improve our results. In central ECMO, LV venting is straightforward, with direct cannulation of the LV apex the most efficacious because the cannula size and length can be optimized. Use of the right superior pulmonary vein may not be as effective because of the resistance posed by the cannula length and size. Peripheral ECMO would require LV venting through a small, anterior left thoracotomy incision. Femoral venous access with an atrial septostomy, as with the centrally placed right superior pulmonary vein cannula, suffers from less-effective cannula drainage. Despite the logistic problems that LV venting presents, the physiology involved would seem to argue that LV venting should be a sine qua non of ECMO for PCS, if we are to make any improvement in our treatment of PCS.

\section{THE COST OF ECMO}

Considering the cost of some of the more expensive components of ECMO, we, the gatekeepers of this technology, can run up quite a bill in trying to save the lives of our patients. With the TandemHeart (CardiacAssist, Inc, Pittsburgh, Pa) and CentriMag (Thoratec Corporation, Pleasanton, Calif) devices at approximately $\$ 10,000$ to 20,000 , the CARIDOHELP (Maquet Cardiopulmonary GmbH, Rastatt, Germany) priced in that range as well (but 4 times that much for the base controller), the Impella similarly priced, and cannulas that can cost a few thousand dollars each, venoarterial ECMO hardware alone can represent a huge cost for patient care. Furthermore, depending on the patient care model used at the bedside, from a single nurse with ECMO capability, the least expensive option, to a bedside nurse with a dedicated ECMO specialist such as a perfusionist, the most expensive option, the cost in terms of human resources can be as much as $\$ 2000$ to $\$ 3000$ per day. And even when the hospital is more than willing to support the effort, sometimes there is just not enough technology or knowledge capability within the institution to address the needs on a given day, which in my experience causes us to stretch our delivery of care beyond our capacity.

With data drawn from the NIS database mentioned previous, Maxwell and coworkers ${ }^{11}$ examined all patients with ECMO support who were discharged between 2002 and 2009. In that article, Maxwell and coworkers ${ }^{11}$ estimated that the cost of ECMO for PCS averaged approximately $\$ 44,000$ per day and $\$ 273,000$ per event. 
At Johns Hopkins, during the past 2 years our cost data have been remarkably similar to those generated by the charge data within the NIS database referred to by Maxwell and coworkers, ${ }^{11}$ albeit 10 years later. In Maryland, where all payors are charged and pay the same for care (eg, Medicare, commercial insurance, and Medicaid all pay the same for any episode of care), cost and charge data have a relatively fixed relationship. In that respect, hospital charges in Maryland reliably reflect true costs. Our survival during the past 2 years for the close to 50 patients who have had PCS has been $37 \%$. The average charges for those patients treated with ECMO were $\$ 226,000$ for the survivors, ranging from $\$ 110,000$ to $\$ 460,0000$, and $\$ 242,000$ for those that died, ranging from $\$ 42,000$ to $\$ 1,028,000$. As capitated care becomes more prevalent, this is going to become a major hurdle, one that cannot be left unaddressed.

\section{THE ETHICS OF ECMO}

The cost of ECMO places a burden on us, the treating physicians, because we must shoulder the responsibility for overseeing the use of this extremely expensive technology in the face of the increasingly limited resources available to us. Shifting perspective completely, however, ECMO burdens us with another layer of responsibility. ECMO creates ethical dilemmas for which almost none of us have been adequately prepared. In an ECMO-capable hospital, the issue is not that no one dies without it (although many days it seems that way), but rather that it is impossible to die with it. Life no longer requires lungs or a heart, and with the addition of dialysis, kidneys are optional as well. One cannot escape from the fact that we, as the gate keepers of this technology, must discipline ourselves to apply it in a manner that honors not only life but also death.

ECMO gives our patients a chance at survival that heretofore they have never had. Unfortunately, it very easily becomes a therapy that shifts into the realm of simply prolonging death, rather than creating a lifesaving opportunity. A further problem is that even colleagues caring for the same patient disagree as to when enough is enough. And, as difficult as that might be for us physicians, in today's world we now must turn to our patients, and much more frequently their families, to participate in the end-of-life discussions that are an inevitable part of ECMO care. The conundrum highlights a variety of very difficult and unanticipated circumstances. First, the issue of consent is made moot when a patient cannot be weaned from bypass and the treating surgeon determines that ECMO is the best therapeutic option. Even though it may occasionally involve input from colleagues, for better or for worse, it is invariably a unilateral decision that rarely involves a request for consent from the family. We may go out to the waiting room to inform our patient's family of the course of intraoperative events, but at that juncture it is uncommon in my experience to ask for permission to institute ECMO. There is still hope for myocardial recovery, and the surgeon certainly is not going to give up on his patient when that is the case. As the ensuing days pass, however, and when medical futility becomes increasingly apparent, as is the case so frequently, we then present an unprepared family with the need for an end-of-life decision. As we all know, when ECMO is running smoothly and vital signs are stable, when patient cognition is evident (many obey commands, some are awake, and some are even extubated), it should be obvious to all of us that a layperson's full understanding of medical futility is too much to expect. As surgeons, almost universally the more responsible that we feel and the more emotionally attached that we become, the more difficult it is for us to remain rational regarding end-of-life decisions. It is no wonder that families struggle mightily with understanding when care is futile when we ourselves do not recognize this situation or will not admit it when it is staring directly at us. It is rare that the patient can participate in any decision making, although it can be incredibly helpful to us and to his loved ones when he or she can. (By the way, this situation should emphasize to all of us the importance of advanced directives, because they have the ability to free our loved ones of the responsibility for making impossible decisions for which they are unprepared and that can leave them with lifelong feelings of guilt, remorse, or even worse.) Commonly, unable to negotiate the difficulty of making any decision, the family votes for aggressive care at all costs. I would argue, however, that this is all avoidable. Just as transplant centers have committees to determine candidate selection, ECMO centers should do the same. The burden of the inevitable ethical and medical decisions that ECMO creates should not be borne by any individual. ${ }^{12}$ Never is it more apparent than in this setting that the wisdom of the group is helpful and should be heeded. As with transplant cases, decision by a committee of experienced professionals can provide objectivity to us, the caregivers, who frequently are incapable of exercising it on our own. Just as importantly, this type of committee can provide guidance and solace to patients and families by relieving them of the responsibility to make decisions for which they are insufficiently informed or emotionally prepared. Although the structure is not mature, we at Johns Hopkins are attempting to form a committee composed of cardiology, pulmonary, and cardiac surgery personnel, both to determine the advisability of initiating ECMO as well as to judge the appropriate time for its withdrawal when care is considered futile. Palliative care and nursing personnel almost certainly should play a role in this oversight as well.

Immediately on the institution of ECMO, programs should prepare patients' families with counseling and educational material that addresses the complications of ECMO, including the possibility that care may become futile with no hope for recovery and with no easy way of dying short of ECMO discontinuation. During the course 
of ECMO, the need for communication with the family on a regular basis has never been more important, not only to inform but to also hold their hands and guide them. For example, a discussion of appropriate duration of ECMO should begin the minute that the process is instituted. In so doing, the education of the family immediately begins, managing expectations and grounding their hope in reality as opposed to fantasy. We should all agree that the specific duration of ECMO support for any specific patient cannot be determined a priori, but we should also recognize that neither should the elasticity of its duration be infinite, and this is a message that needs to be given to families. The responsibility of those involved in an ECMO program involves the willingness and capability to shepherd our patients and their families through what is at times a most heart-wrenching experience.

\section{OUR RESPONSIBILITY TO SOCIETY AND OUR PATIENTS}

I would conclude my discussion of ECMO for PCS with these thoughts. Never has it been more evident than in the case of ECMO that we, the caregivers, cannot simply give our patients a menu of therapeutic options from which to choose. The institution of ECMO necessitates the appropriate use of this therapy, as well as the counseling of patients and their loved ones, who need guidance, education, and our direction and leadership. As our technologic abilities increasingly become boundless, never have these guiding words from the Hippocratic Oath been more appropriate:

I will apply, for the benefit of the sick, all measures which are required, avoiding those twin traps of overtreatment and therapeutic nihilism. I will remember that there is art to medicine as well as science, and that warmth, sympathy, and understanding may outweigh the surgeon's knife or the chemist's drug.

\section{Conflict of Interest Statement}

Author has nothing to disclose with regard to commercial support.
I thank Dr Todd Crawford, the Hugh R Sharp, Jr Research Fellow in Cardiac Surgery at the Johns Hopkins University School of Medicine, for his help in the data analysis that underlies a significant portion of this article.

\section{References}

1. Hill JD, O’Brien TG, Murray JJ, Dontigny L, Bramson ML, Osborn JJ, et al. Prolonged extracorporeal oxygenation for acute post-traumatic respiratory failure (shock-lung syndrome). Use of the Bramson membrane lung. $N$ Engl J Med. 1972;286:629-34.

2. Zapol WM, Snider MT, Hill JD, Fallat RJ, Bartlett RH, Edmunds LH, et al. Extracorporeal membrane oxygenation in severe acute respiratory failure. A randomized prospective study. JAMA. 1979;242:2193-6.

3. McCarthy FH, McDermott KM, Kini V, Gutsche JT, Wald JW, Xie D, et al Trends in U.S. extracorporeal membrane oxygenation use and outcomes: 2002-2012. Semin Thorac Cardiovasc Surg. 2015;27:81-8.

4. Fukuhara S, Takeda K, Garan AR, Kurlansky P, Hastie J, Naka Y, et al. Contemporary mechanical circulatory support therapy for postcardiotomy shock. Gen Thorac Cardiovasc Surg. 2016;64:183-91.

5. Rastan AJ, Dege A, Mohr M, Doll N, Falk V, Walther T, et al. Early and late outcomes of 517 consecutive adult patients treated with extracorporeal membrane oxygenation for refractory postcardiotomy cardiogenic shock. J Thorac Cardiovasc Surg. 2010;139:302-11.e1.

6. Samuels LE, Kaufman MS, Thomas MP, Holmes EC, Brockman SK, Wechsler AS. Pharmacological criteria for ventricular assist device insertion following postcardiotomy shock: experience with the Abiomed BVS system. J Card Surg. 1999;14:288-93.

7. Hernandez AF, Grab JD, Gammie JS, O'Brien SM, Hammill BG, Rogers JG, et al. A decade of short-term outcomes in post cardiac surgery ventricular assist device implantation: data from the Society of Thoracic Surgeons' National Cardiac Database. Circulation. 2007;116:606-12.

8. Griffith BP, Anderson MB, Samuels LE, Pae WE Jr, Naka Y, Frazier OH. The RECOVER I: a multicenter prospective study of Impella 5.0/LD for postcardiotomy circulatory support. J Thorac Cardiovasc Surg. 2013;145:548-54.

9. Lucas SK, Schaff HV, Flaherty JT, Gott VL, Gardner TJ. The harmful effects of ventricular distention during postischemic reperfusion. Ann Thorac Surg. 1981 32:486-94.

10. Kotani Y, Honjo O, Davey L, Chetan D, Guerguerian AM, Gruenwald C. Evolution of technology, establishment of program, and clinical outcomes in pediatric extracorporeal membrane oxygenation: the "sickkids" experience. Artif Organs 2013;37:21-8

11. Maxwell BG, Powers AJ, Sheikh AY, Lee PH, Lobato RL, Wong JK. Resource use trends in extracorporeal membrane oxygenation in adults: an analysis of the Nationwide Inpatient Sample 1998-2009. J Thorac Cardiovasc Surg. 2014; 148:416-21.e1.

12. Ramanathan K, Cove ME, Caleb MG, Teoh KL, Maclaren G. Ethical dilemmas of adult ECMO: emerging conceptual challenges. J Cardiothorac Vasc Anesth 2015;29:229-33

Key Words: postcardiotomy shock, extracorporeal membrane oxygenation, outcomes, cost of ECMO, ethics of ECMO 